\title{
Research of energy efficiency direct-heating systems with sequential connection of space heaters with different methods of heat consumption regulation
}

\author{
Maxim N. Morozova and Pavel A. Strizhak \\ National Research Tomsk Polytechnic University, 634050 Tomsk, Russia
}

\begin{abstract}
A model of the building heating system, consisting of energy source, a distributed automatic control system, elements of individual heating unit and heating system is designed. Application Simulink of mathematical package Matlab is selected as a platform for the model. There are the specialized application Simscape libraries in aggregate with a wide range of Matlab mathematical tools allow to apply the "acausal" modeling concept. The conducted research of single-pipe heating system configuration and automatic control system allowed comparing the integral parameters of the systems with local and individual regulation. The results of research of thermal condition premises, situated in the extreme movement direction of the coolant are given. The conclusions about the possibility of increasing the operational efficiency of single-pipe heating system configuration in the implementation of distributed control systems are presented.
\end{abstract}

\section{Introduction}

In recent years issues of energy conservation, improving energy and resource efficiency are considered decisive in many countries $[1,2]$.

Particular attention, as a rule, is given to activities aimed at improving the energy efficiency of administrative and industrial purposes buildings and facilities [3-9].

There are several active requirements for a modern heating system. On the one hand it is necessary to maintain the microclimate parameters at a comfortable level and on the other - it is required increasing energy efficiency of engineering building life support systems.

The aim of this work is to investigate a single-pipe building heating system in case of local regulation in heating unit and also in the case of individual regulators.

\section{Simulation object}

As a simulation object, a district heating system of a typical administrative building (for Russia) has been selected. The system consists of the individual heating unit (IHU), mainline inlet and outlet pipes,

\footnotetext{
${ }^{a}$ Corresponding author: tpu_chm@tpu.ru
}

This is an Open Access article distributed under the terms of the Creative Commons Attribution License 4.0, which permits unrestricted use, distribution, and reproduction in any medium, provided the original work is properly cited. 


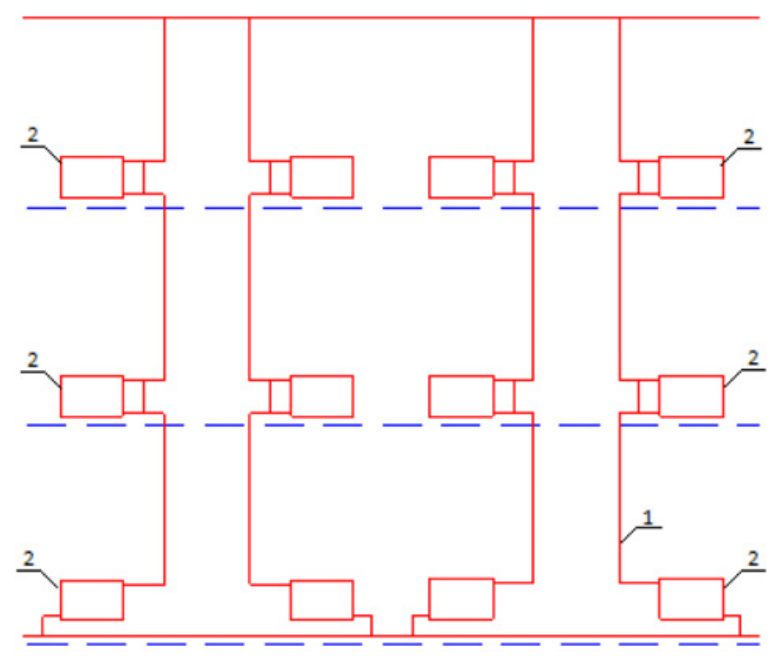

Figure 1. A schematic diagram of a single-pipe building heating system by a vertical configuration: 1 - water pipe, 2 - heating appliance.

risers, heating appliance and control valve. Heat supply of the building is provided by the central heating unit at the temperature chart $95 / 70^{\circ} \mathrm{C}$.

Entry heat supply system into the building carried out through heat metering point of IHU. The IHU has been designed under the "independent scheme" using pump circulation and mixing the coolant from the return pipeline to the feed $[10,11]$. The building heating system's feature is the availability of both single- and double-pipe configurations.

As modeling object a vertical single-pipe configuration with overhead coolant distribution and heating appliances, connected in sequential groups, has been selected in this research work (Fig. 1).

The system is a combined (heating appliances installed on the upper floors provided with a bypass, the lower floor - flow system).

\section{Model of the building district heating system}

The thermal model of the building has been developed to evaluate the energy efficiency of pipe heating systems with different methods of regulation.

The application Simulink of the mathematical package Matlab [12] has been selected as a platform for a model. An extension package Simscape, which implements a "physical" simulation concept [13], has also been applied to develop the model.

Model implementation in the Matlab package is based on representing of each individual functional component $[12,13]$ in the form of s-functions and subsystems blocks (Figs. 2, 3).

The law of energy conservation for a typical premise is at the basis of the thermal model of the building heating system [14].

To simulate different mechanisms of heat transfer between model components laws Fourier, describing the mechanism of conductivity heat transfer and the Newton-Richman (convective heat transfer) has been applied [14].

The model universality allows applying it for a variety of purposes: energy efficiency evaluation of various configurations heating systems, methods of heat consumption regulation, as well as research problems of reliability of energy supply systems and emergency situations forecasting of heat networks. 


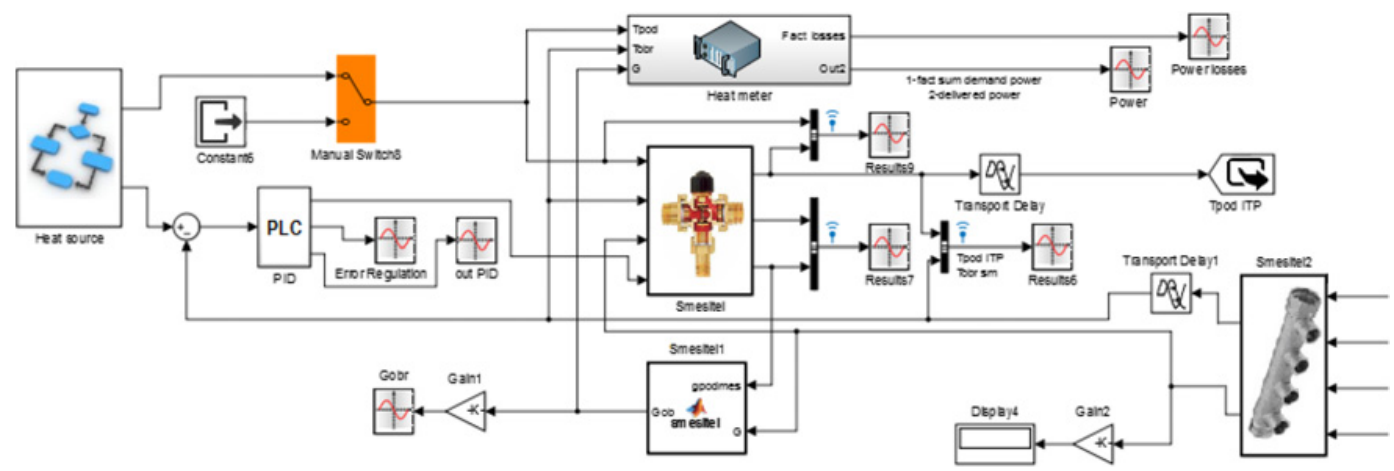

Figure 2. The main thermal model blocks of the building district heating system.

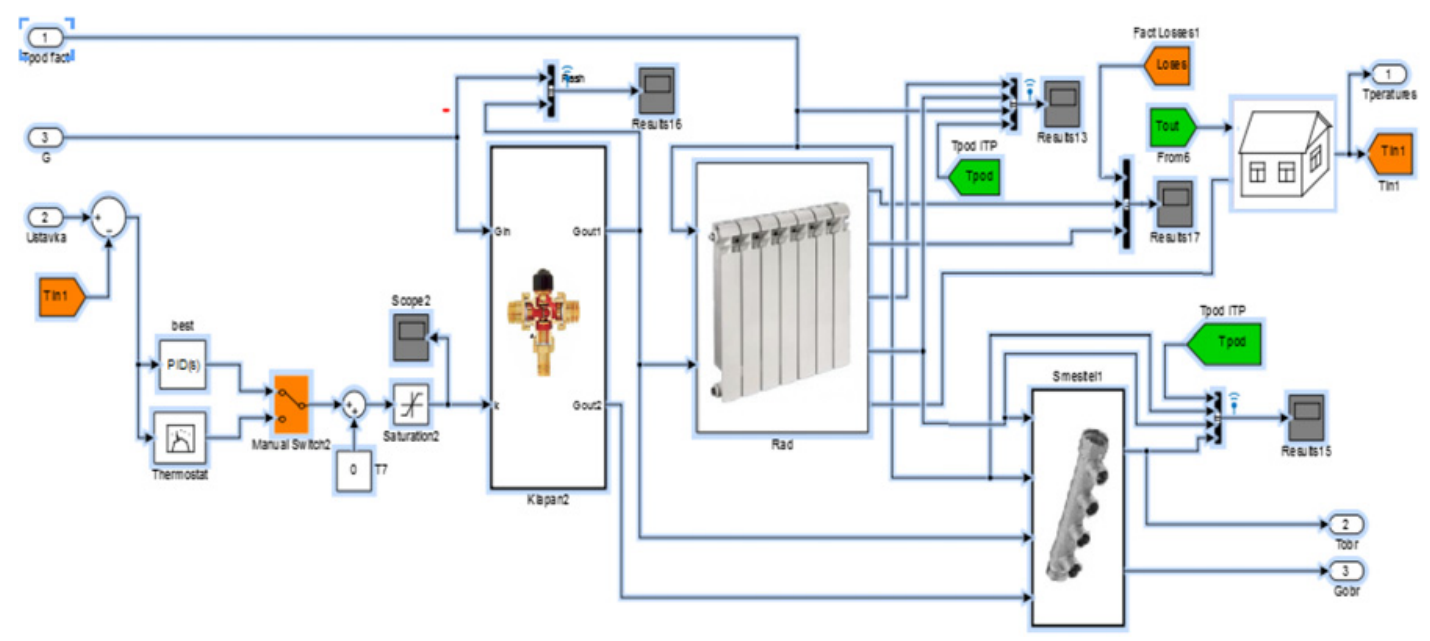

Figure 3. A part of premise model.

In this context the model can be used as a tool at the technical-and-economic assessment development of energy management systems in accordance with ISO 50001:2011 "Energy management systems - Requirements with guidance for use" [15].

An example of applied problem is realization of an individual building thermal mode [16-19]. This assumes implementation of low heat demand mode, where the temperature of indoor air is reduced to an allowable parameters "heat-humidity" mode, regulatory documents, as well as economic reasons.

\section{Modelling results}

To achieve the set purpose of investigations, a series of numerical experiments has been carried out, aimed to analyze the influence of the external disturbing factor (outside temperature Tout) on premises thermal mode, containing the heating system:

1) with individual regulation;

2) with local regulation in IHU without individual. 
Table 1. Results of system reaction at the external disturbing factor influence.

\begin{tabular}{|c|c|c|c|}
\hline Outdoor temperature & \multicolumn{3}{|c|}{ Regulation time treg, s $\times 10^{4}$} \\
\cline { 2 - 4 }$T_{\text {out }},{ }^{\circ} \mathrm{C}$ & Premise 3rd floor (No 3) & Premise 2nd floor (No 2) & Premise 1st floor (No 1) \\
\hline $5 \ldots 0$ & 0,0608 & 0,0776 & 0,2655 \\
\hline $0 \ldots-5$ & 0,0628 & 0,1296 & 0,2661 \\
\hline$-5 \ldots-10$ & 0,0621 & 0,1284 & 0,2243 \\
\hline$-10 \ldots-15$ & 0,0623 & 0,0872 & 5,9 \\
\hline$-15 \ldots-20$ & 0,0598 & 0,0867 & 4,55 \\
\hline$-20 \ldots-25$ & 0,0585 & 0,088 & 4,58 \\
\hline$-25 \ldots-30$ & 0,0582 & 0,0925 & 4,6 \\
\hline$-30 \ldots-35$ & 0,067 & 0,1067 & 4,63 \\
\hline$-35 \ldots-40$ & 0,0532 & 0,1607 & 4,117 \\
\hline
\end{tabular}

Table 2. Results of building thermal mode research in case of local regulation with weather compensator at the external disturbing factor influence.

\begin{tabular}{|c|c|c|c|}
\hline Outdoor temperature & \multicolumn{3}{|c|}{ Indoor temperature $T_{\text {in }},{ }^{\circ} \mathrm{C}$} \\
\cline { 2 - 4 }$T_{\text {out }},{ }^{\circ} \mathrm{C}$ & Premise 3rd floor (No 3) & Premise 2nd floor (No 2) & Premise 1st floor (No 1) \\
\hline 5 & 26,37 & 24,68 & 22,51 \\
\hline 0 & 25,68 & 23,92 & 21,64 \\
\hline-5 & 25,49 & 23,49 & 20,87 \\
\hline-10 & 25,32 & 23,05 & 20,04 \\
\hline-15 & 25,15 & 22,61 & 19,24 \\
\hline-20 & 24,97 & 22,18 & 18,45 \\
\hline-25 & 24,79 & 21,75 & 17,66 \\
\hline-30 & 24,59 & 21,32 & 16,89 \\
\hline-35 & 24,59 & 21,06 & 16,27 \\
\hline
\end{tabular}

In each series of experiments three rooms located on different floors of the building (Fig. 1) has been considered: vertical single-pipe configuration with sequential connections of heating appliances. As an external disturbing factor outside air temperature $T_{\text {out }}$ has been accepted. Temperature change has been set in the range $[-40 ; 5]^{\circ} \mathrm{C}$ with increments of $5^{\circ} \mathrm{C}$.

Comparative analysis of the first series modeling results showed that individual control of heating appliances provides stabilization of the controlled parameter - indoor air temperature $T_{\text {in }}$.

Estimation of the transient processes quality has been conducted by the regulation time treg. After modeling the specified temperature range of the external disturbing factor Tout obtained data have been processed. Results of this process are summarized in Table 1.

Analysis of data (Table 1) leads to the conclusion about the regulation time increasing for the 1 st floor premise. The latter is explained by lack of coolant temperature at the inlet to the heating appliances. The individual (distributed) automatic control system cannot cope with its main objective - stabilizing indoor room temperature.

Comparative analysis of the second series modeling results showed that under the considered weather conditions the absence of individual regulation does not allow the heating system to maintain optimal thermal conditions of the premises (Table 2).

Also, the analysis shows that the 3 rd floor indoor air temperature $T_{\text {in }}$ is inflated in the whole range of external disturbing factor influence Tout during the entire heating season.

On the contrary, the 1st floor premise is characterized by a scarce heat supply. Thus the heating system does not satisfy normative values of microclimate parameters and causes extra heat loss due to inflated indoor air temperature $T_{\mathrm{in}}$. 
Uneven coolant distribution at heating appliances is the most important disadvantage of single-pipe heating systems. This problem cannot be solved even in case of installation modern controller with weather compensator ("weather-dependent" algorithm) in IHU.

Research has been shown that total modernization of heat supply system by installing individual regulators of heat consumption (distributed system) in addition to centralized controller allows getting qualitatively new opportunities. In this case, it becomes available to maintain the individual premises thermal modes, precise control in accordance with the PID, PD or PI-laws exclude overruns heat, which caused by inflated indoor air temperature $T_{i n}$.

In this case there is an automatic coolant redistribution between heating appliances. Functioning of the considered system becomes the most optimal (in the hydraulic balance term) in the implementation of automatic balancing valves, which compensate the negative influence of individual regulators.

\section{Conclusions}

A model of the building district heating system, which allows investigating the problems of widespread single-pipe heating systems in closed to reality operating conditions has been developed.

The conducted researches provide an opportunity to evaluate the efficiency of various heating systems and its regulation variants: centralized in IHU using "weather-dependent" algorithm separately and also combined with individual regulation of heat consumption.

It is shown that even a single-pipe heating system configuration allows maintaining the building indoor climate parameters in the optimal range with less power consumption only in case of implementation of distributed control system (a combination of local regulation in IHU and individual - in each premise).

The reported study is supported by the Ministry of Education and Science of the Russian Federation Grant (project 2.1321.2014).

\section{References}

[1] V. Roshchanka, M. Evans, Playing hot and cold: how can Russian heat policy find its way toward energy efficiency (Pacific Northwest National Laboratory, Washington, 2012)

[2] G. Keikkala, A. Kask, J. Dahl, V. Malyshev, V. Kotomkin, Energ. Policy B 35, 1452 (2007)

[3] A. Korppo, N. Korobova, Energ. Policy B 42, 213 (2012)

[4] A. Boute, Pace Envtl. L. Rev. B 29, 746 (2012)

[5] Z. Wang, Y. Ding, G. Geng, N. Zhu, Energy Convers. Manage. B 77, 233 (2014)

[6] G. Dall'O, L. Sarto, Energy and Build. B 67, 298 (2013)

[7] G. Mustafaraj, D. Marini, A. Costa, M. Keane, Appl. Energy B 130, 72 (2014)

[8] T. Berger, C. Amann, H. Formayer, A. Korjenic, B. Pospischal, C. Neururer, R. Smutny, Energy and Build. B 80, 517 (2014)

[9] M.D. Moldovan, I. Visa, M. Neagoe, B.G. Burduhos, Energy Procedia B 48, 924 (2014)

[10] M. Zago, A. Casalegno, R. Marchesi, F. Rinaldi, Energies B 4, 2115 (2011)

[11] O. Ibrahim, F. Fardoun, R. Younes, H. Louahlia-Gualous, Build. Environ. B 72, 259 (2014)

[12] M. Kiyan, E. Bingöl, M. Melikoglu, A. Albostan, Energy Convers. Manage. B 72, 147 (2013)

[13] D. Broman, P. Fritzson, Proceedings of the 2nd International workshop on equation-based objectoriented languages and tools, 59 (Paphos, Cyprus, 2008)

[14] P. Lauenburg, J. Wollerstrand, Proceedings of the 11th International Building Performance Simulation Association Conference, 150 (Glasgow, 2009) 


\section{EPJ Web of Conferences}

[15] C. Eccleston, F. March, T. Cohen, Inside Energy: The Handbook for Implementing an ISO 50001 Energy Management Systems (CRC Press, 2011)

[16] M. Wallace, R. McBride, S. Aumi, P. Mhaskar, J. House, T. Salsbury, Chem. Eng. Sci. B 69, 45 (2012)

[17] S. Privara, Z. Vana, E. Zacekova, Energy and Build. B 55, 341 (2012)

[18] M. Maasoumy, M. Razmara, M. Shahbakhti, A. Sangiovanni Vincentelli, Energy and Build. B 77, 377 (2014)

[19] H.F. Scherer, M. Pasamontes, J.L. Guzman, J.D. Alvarez, E. Camponogara, J.E. Normey-Rico, J. Process Control, B 24, 740 (2014) 